\title{
Incidence of Leishmania Donovani Infection among Agro-pastoralists Tribes in Um-alkhare and Bazura Villages, Gedarif State, Eastern Sudan
}

Lana M El-amin ${ }^{1}$, Hshim Balla $\mathbf{M}^{2}$, Abakar $\mathbf{A D}^{1}$, Khalid KE ${ }^{3}$, Elbadry $A A^{4}$ and Nour $B M^{1,5 *}$

${ }^{1}$ Department of Medical Parasitology, University of Gezira, Wad Medani, Sudan

${ }^{2}$ Department of Internal Medicine, University of Gedarif, Al Qadarif, Sudan

${ }^{3}$ Department of Laboratory Medicine, Albaha University, Al Bahah, Saudi Arabia

${ }^{4}$ Medical Parasitology Department, Lab of Molecular Medical Parasitology (LMMP), Diagnostic \& Research Unit of Parasitic Diseases (DRUP), Kasr Al-Ainy School of Medicine, Cairo University, Cairo, Egypt

${ }^{5}$ Department of Parasitology, Blue Nile Research National Institute for Communicable Diseases, University of Gezira, Wad Medani, Sudan

*Corresponding author: Nour BYM, Faculty of Medical Laboratory Sciences, Department of Medical Parasitology, University of Gezira, Wad Medani, Sudan, Tel: +5472142278; E-mail: Lana.alamin@gmail.com

Received date: October 20, 2017; Accepted date: November 24, 2017; Published date: December 02, 2017

Copyright: ( $2017 \mathrm{El}$-amin LM, et al. This is an open-access article distributed under the terms of the Creative Commons Attribution License, which permits unrestricted use, distribution, and reproduction in any medium, provided the original author and source are credited.

\begin{abstract}
Visceral leishmaniasis $(\mathrm{VL})$ is a life-threatening parasitic disease, transmitted by a sand fly. A survey aimed to estimate the VL incidence in Um-alkhare and Bazura villages located in endemic southern part of Gedaref State, Eastern Sudan, in the period among (March 2014-February 2015). This study conducted among Agro-pastoralists tribes in the two villages comparing the epidemiological and clinical spectrum of VL infection. One hundred seventy five (109 male and 66 females) clinical suspected for $V L$ were examined in the two rural hospitals, their age range between (3-48 years old). Bone marrow (BM) and lymph node (LN) smears were aspirated for parasitological examination and the serum was tested by using rk39 for Leishmania donovani antibodies. Socio-demographic and other determinants governing VL were also studied. The incidence rate of visceral leishmaniasis from was $42.8 / 1,000$ person per year,and $57.1 \%$ for the prevalence rate. Microscopic examination for VL was confirmed in 64 patients (49 males, 15 females) from BM and LN aspirate smears. rK39 test gave prevalence rate of $36.6 \%$ and $42.3 \% \mathrm{VL}$ antibodies for BM and LN specimen respectively. Sensitivity and specificity for rK39 was determined to be $79 \%$ and $70 \%$, respectively. Patient's positive for microscopic tests showed clinical signs and symptoms such as, severe irregular fever, splenomegaly and LN enlargement. Hausa tribe has a highest VL infection (26.7\%), followed by Masaleet (18.7\%). Infection rate was reported to occur during October coinciding with high transmission season. It was also observed that prevailing Balantis trees, cracking soil and Leishmania reservoir have direct correlation with VL infection. Further genetic studies based on wide community survey are highly recommended to verify susceptibility of different agro-pastoralists tribes to VL infection.
\end{abstract}

Keywords: Visceral leishmaniasis incidence; Sudanese tribes; Macrophage; Clinical; Lymph node; Antibodies

\section{Introduction}

Leishmaniasis is a vector-borne disease, caused by obligate intramacrophage protozoa and endemic in large areas of the tropics, subtropics and the Mediterranean basin [1]. The increase in leishmaniasis' worldwide incidence is mainly attributed to the contribution of several risk factors that are clearly man made and include massive migration, deforestation, urbanization, immunosuppressant, malnutrition and treatment failure [2]. The disease is classified as one of the most important neglected diseases based on the limited resources invested in diagnosis, treatment, and control and its strong association with poverty [3]. VL or kala-azar as known is a fatal systemic disease caused by Leishmaniadonovani complex, which has been responsible for great morbidity and mortality in Sudan [4]. Gedaref state is the main endemic area of VL in eastern Sudan, $410 \mathrm{~km}$ south-east of Khartoum. The surround villages in the state with high incidence of VL are located along two rivers (Atbarah and Rahad) in areas of low altitude and high rainfall (Figure 1).
Recent surveys of disease burden still show consistently high infection. The overall incidence rate of VL over the past year was 7.0/1000 persons per year [5]. Still there are marked differences in the ratios of clinical to sub-clinical infections of $L$. donovani and exposure to infection among different ethnic groups inhabited the villages of Gedaref state, eastern Sudan [6]. This study encompasses two villages (Um-alkhare and Bazura), located on the eastern bank of the Rahad River, a tributary of the Blue Nile that marks the eastern border of the Dinder National Park in Gedaref state. The selected villages were founded in 1969 by members of the Masaleet tribe who migrated from western Sudan and Hausa tribe who migrated from northern Nigeria. The inhabitants are mainly farm laborers and subsistence farmers and live in grass huts without latrines, the standard of hygiene is poor. Umalkhar is located $300 \mathrm{~km}$ south of Bazura, also situated along the Rah River; the majority of inhabitants can therefore be expected to have been born in the village. Houses in the villages are thatched grass huts and all have latrines with large courtyards and hold Blanitis trees contain domestic stables. The main tribes in two villages are seminomadic pastoralists of the Masaleet, Hausa, Bega, Bargo, Marareet, Dago, Kebed, Fore, Gemer, and Garib tribes.

The diagnosis of VL is confirmed by demonstration of the intracellular parasite by aspirates of the spleen, bone marrow, lymph 
Citation: Lana ME, Hshim BM, Abakar AD, Khalid KE, Elbadry AA, et al. (2017) Incidence of Leishmania Donovani Infection among Agropastoralists Tribes in Um-alkhare and Bazura Villages, Gedarif State, Eastern Sudan. J Trop Dis 5: 252. doi:10.4172/2329-891X. 1000252

Page 2 of 5

node or liver biopsy. Sera diagnosis techniques based on the enzymelinked immunosorbent assay, the direct agglutination test (DAT), and the rK39-based rapid diagnostic test have been developed for field use [7].

This study was aimed to estimate the incidence of Leishmaniadonovani infection among Agro-pastoralists tribes in rural hospitals Um alkhare and Bazura villages in Gedaref state eastern Sudanfor VL suspected patients.

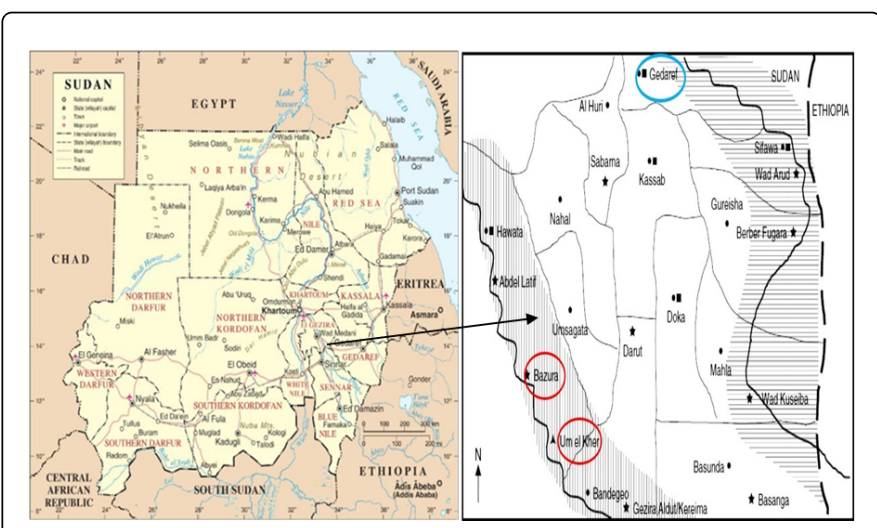

Figure 1: Map of southern Gedaref state, Eastern Sudan [8].

\section{Patients and Methods}

\section{Collection of demographic data}

This is a descriptive cross sectional study, took place in Um-alkhare and Bazura villages, in Gedarif state, eastern Sudan.The study subjects include $109(62.3 \%)$ males and $66(37.7 \%)$ females, their mean age was $16.48 \pm 12.6$ years, range between 2-54 years, they referred to rural hospitals of Um-alkhare and Bazurain the period from March 2014 to February 2015. The study subjects were clinically evaluated by ascertained doctors and parasitological examination confirmed VL patients. The diagnosis was done by direct demonstration of amastigotes in Giemsa-stained BM, LN smears, and preformation of rk-39 ICT from peripheral blood sample.

The study was approved by the ethics committee of the Ministry of Health in Gedarif state. Informed written consent was taken from each patient or from the legal guardian (in case of minor) before performing invasive procedures like bone-marrow aspiration and venipuncture for blood collection.

\section{Bone marrow aspiration}

In this procedure, the patient kept lying on the palpated and foxed side. The area was cleaned by tincture iodine and rectified spirit and local anesthesia applied to the target area up to $1 \mathrm{ml}$. Bone marrow sample was aspirated by gentle suction using $10 \mathrm{ml}$ disposable syringe.
Immediately after, thin film of the aspirate was made on at least three microscopic slides. Films were allowed to dry on air, and the back of the slide was rubbed rapidly with a finger to slightly warm the glass and drive off moisture, then slides carried to the laboratory for staining and microscopic examination as indicated earlier $[8,9]$.

\section{Lymph node aspiration (LNA)}

The LNA entire procedure was performed in $<1$ minute without local anesthesia. The patient lay on a bed, the overlying skin was cleaned and the largest palpable inguinal or femoral lymph node was held firmly between thumb and index fingers while a 21-gauge 1.25inch hypodermic needle was inserted. The aspirate was expelled onto a glass slide, smeared, air-dried, fixed with $100 \%$ methanol, and stained with Giemsa [10].

\section{Rk-39 test}

For detection of human visceral leishmaniasis antibodies against rk39 antigen, the IT-LEISH kit was purchased from Bio-Rad, France. The blood samples include capillary blood from fingertips, and whole blood collected by venipuncture in EDTA-container. The test was performed and interpreted according to the manufacturer instruction.

\section{Ethical considerations}

The Ethical approval obtained from the ethical committee of the Blue Nile National for Communicable Diseases, and permission obtained from Gedarif State Ministry of Health Authorities and informed consent obtained from the participants.

\section{Data analysis}

The data analyzed using SSPS 18 software (SPSS Inc. Chicago, IL, USA), which estimates the mean of age, standard deviations and the frequency of tribes and its relationship between data of demographic factors and diagnostic techniques. The sensitivity, specificity, positive predictive values (PPVs) and negative predictive values (NPVs) were computed along with the $95 \%$ confident interval of both techniques were compared using $\chi^{2}$ test (or chi-square test), with significant level $<0.05$. The incidence rate for VL was calculated as the number of cases who were either confirmed VL or diagnosed in retrospect per number of person-years follow-up in the total population.

\section{Result}

A total of 175 clinically suspected patients (109 male and 66 females) were living in two rural villages in Gedaref State-Eastern Sudan. Bone marrow or lymph node aspirates were performed for each patient. The patients were divided into four categories based on their age (Table 1). In both gender, patients age less than 15 years showed high frequency of VL infection and the overall rate of infection is high among females 22/66 (71.2\%) than males 20/109 (48.4\%).

\begin{tabular}{|l|l|l|l|l|l|}
\hline \multirow{2}{*}{ Sex } & Age Ranges & Direct Microscopy & \multicolumn{2}{|l|}{ rK39 } \\
\cline { 3 - 6 } & & Positive & Negative & Positive & Negative \\
\hline Males & $<15$ & $20(38.5 \%)$ & $32(61.5 \%)$ & $22(42.3 \%)$ & $30(57.7 \%)$ \\
\hline
\end{tabular}


Citation: Lana ME, Hshim BM, Abakar AD, Khalid KE, Elbadry AA, et al. (2017) Incidence of Leishmania Donovani Infection among Agropastoralists Tribes in Um-alkhare and Bazura Villages, Gedarif State, Eastern Sudan. J Trop Dis 5: 252. doi:10.4172/2329-891X. 1000252

Page 3 of 5

\begin{tabular}{|l|l|l|l|l|l|l|}
\hline \multirow{5}{*}{} & $15-22$ & $12(48.0 \%)$ & $13(52.0 \%)$ & $12(48.0 \%)$ & $13(52.0 \%)$ & $25(100.0 \%)$ \\
\cline { 2 - 7 } & $23-30$ & $11(73.3 \%)$ & $4(26.7 \%)$ & $11(73.3 \%)$ & $4(26.7 \%)$ & $15(100.0 \%)$ \\
\cline { 2 - 7 } & $>30$ & $10(58.8 \%)$ & $7(41.2 \%)$ & $11(64.7 \%)$ & $6(35.3 \%)$ & $17(100.0 \%)$ \\
\cline { 2 - 7 } & Total & $53(48.6 \%)$ & $56(51.4 \%)$ & $56(51.4 \%)$ & $53(48.6 \%)$ & $109(100.0 \%)$ \\
\hline \multirow{3}{*}{ Females } & $<15$ & $22(59.5 \%)$ & $15(40.5 \%)$ & $21(56.8 \%)$ & $16(43.2 \%)$ & $37(100.0 \%)$ \\
\cline { 2 - 7 } & $15-22$ & $10(83.3 \%)$ & $2(16.7 \%)$ & $9(75.0 \%)$ & $3(25.0 \%)$ & $12(100.0 \%)$ \\
\cline { 2 - 7 } & $23-30$ & $6(75.0 \%)$ & $2(25.0 \%)$ & $7(87.5 \%)$ & $1(12.5 \%)$ & $8(100.0 \%)$ \\
\cline { 2 - 8 } & $>30$ & $9(100.0 \%)$ & $0(0.0 \%)$ & $8(88.9 \%)$ & $1(11.1 \%)$ & $9(100.0 \%)$ \\
\cline { 2 - 8 } & Total & $47(71.2 \%)$ & $19(28.8 \%)$ & $45(68.2 \%)$ & $21(31.8 \%)$ & $66(100.0 \%)$ \\
\hline \multirow{2}{*}{ Total } & 175 & & & & \\
\hline
\end{tabular}

Table 1: Direct microscopy and rk39 with age ranges and sex $(n=175)$.

\begin{tabular}{|c|c|c|c|c|c|c|c|}
\hline \multirow[t]{2}{*}{ Direct Microscopy } & \multicolumn{3}{|l|}{ Education } & \multicolumn{3}{|c|}{ Economic status } & \multirow{3}{*}{$\begin{array}{l}\text { Total } \\
75 \\
(100.0 \%)\end{array}$} \\
\hline & Illiterate & Basic & Secondary & Poor & Mid & Rich & \\
\hline Positive & $52(69.3 \%)$ & $20(26.7 \%)$ & $\begin{array}{l}3 \\
(4.0 \%)\end{array}$ & $61(81.3 \%)$ & $\begin{array}{l}10 \\
(13.3 \%)\end{array}$ & $\begin{array}{l}4 \\
(5.3 \%)\end{array}$ & \\
\hline Negative & $64(64.0 \%)$ & $34(34.0 \%)$ & $\begin{array}{l}2 \\
(2.0 \%)\end{array}$ & $78(78.0 \%)$ & $\begin{array}{l}22 \\
(22.0 \%)\end{array}$ & $\begin{array}{l}0 \\
(0.0 \%)\end{array}$ & $100(100.0 \%)$ \\
\hline Total & $116(66.3 \%)$ & $54(30.9 \%)$ & $\begin{array}{l}5 \\
(2.9 \%)\end{array}$ & $\begin{array}{l}139 \\
(79.4 \%)\end{array}$ & $\begin{array}{l}32 \\
(18.3 \%)\end{array}$ & $\begin{array}{l}4 \\
(2.3 \%)\end{array}$ & $175(100.0 \%)$ \\
\hline
\end{tabular}

Table 2: Educational and economic factors comparative with direct microscopy.

As shown in Table 2, illiteracy (52\%) and poor economic status (61\%) represented as the major factors contribute to the burden of VL. Looking to the environmental factors that may contribute to the prevalence of VL among study subject, domestic animals reported high frequency among patients positive to the direct microscopy test compared with the negative subjects (Table 2).

\begin{tabular}{|l|l|l|l|l|l|l|l|l|}
\hline \multirow{2}{*}{$\begin{array}{l}\text { Direct } \\
\text { Microscopy }\end{array}$} & \multicolumn{3}{|l|}{ Garment } & \multicolumn{3}{l|}{$\begin{array}{l}\text { Balantis } \\
\text { trees }\end{array}$} & \multicolumn{3}{l|}{ Crack Land } & \multicolumn{2}{l|}{$\begin{array}{l}\text { Domestic } \\
\text { animal }\end{array}$} \\
\cline { 2 - 10 } & Yes & No & Yes & No & Yes & No & Yes & No \\
\hline Positive & 69 & 6 & 68 & 7 & 72 & 3 & 65 & 90 \\
\hline Negative & 86 & 14 & 95 & 5 & 94 & 6 & 10 & 10 \\
\hline Total & 155 & 20 & 163 & 12 & 166 & 9 & 75 & 100 \\
\hline
\end{tabular}

Table 3: Environmental factors contribute to the prevalence of VL among study cases.
Although, our data showed no significant difference between use of Garment, Balantis trees, Crack land and Domestic animal and positive cases by the direct microscopy technique $(\mathrm{P}=0.217 ; \mathrm{P}=0.262 ; \mathrm{P}=0.553$ and $\mathrm{P}=0.493$ ) respectively.

All positive cases for VL by using the direct microscopy test, were clinically having remarkable irregular fever, emaciation, and enlargement of both spleen and lymph nodes compared to negative suspects (Table 3).

Hausa and Masaleet are the more frequently resident tribes encompassing positively suspected patients followed by Marareet, Western Sudan tribes, and Bargo. The frequency of suspected patients negative to VL is much higher among Bega (80.0\%), Bargo (68.4\%) and western Sudan tribes (63.6\%) (Tables 4 and 5).

\begin{tabular}{|l|l|l|l|l|l|l|l|l|l|l|l|l|l|l|l|}
\hline \multirow{2}{*}{$\begin{array}{l}\text { Direct } \\
\text { Microscopy }\end{array}$} & \multicolumn{3}{|l|}{ Irregular Fever } & \multicolumn{3}{l|}{ Fever Period } & \multicolumn{2}{l|}{ Emaciation } & \multicolumn{3}{l|}{ Appetite } & \multicolumn{2}{l|}{ Enlargement of Organs } \\
\cline { 2 - 16 } & No & Mild & $\begin{array}{l}\text { Re- } \\
\text { mark }\end{array}$ & No & $\begin{array}{l}>2 \\
\text { week }\end{array}$ & No & Mild & Remark & Normal & Decrease & Increase & No & SP & LN & $\begin{array}{l}\text { SP } \\
8 L N\end{array}$ \\
\hline Frequency & 17 & 113 & 45 & 16 & 159 & 53 & 91 & 31 & 70 & 103 & 2 & 64 & 32 & 8 & 71 \\
\hline
\end{tabular}


Citation: Lana ME, Hshim BM, Abakar AD, Khalid KE, Elbadry AA, et al. (2017) Incidence of Leishmania Donovani Infection among Agropastoralists Tribes in Um-alkhare and Bazura Villages, Gedarif State, Eastern Sudan. J Trop Dis 5: 252. doi:10.4172/2329-891X. 1000252

Page 4 of 5

\begin{tabular}{|c|c|c|c|c|c|c|c|c|c|c|c|c|c|c|c|}
\hline Positive & 1 & 44 & 30 & 1 & 74 & 11 & 44 & 20 & 17 & 57 & 1 & 6 & 17 & 4 & 48 \\
\hline Negative & 16 & 69 & 15 & 15 & 85 & 42 & 47 & 11 & 53 & 46 & 1 & 58 & 15 & 4 & 23 \\
\hline Total & \multicolumn{3}{|c|}{175} & \multicolumn{2}{|c|}{175} & \multicolumn{3}{|l|}{175} & \multicolumn{3}{|c|}{175} & \multicolumn{4}{|c|}{175} \\
\hline
\end{tabular}

Table 4: Clinical finding in study cases evaluated by direct microscopy.

\begin{tabular}{|l|l|l|l|}
\hline \multirow{2}{*}{ Tribe } & \multicolumn{2}{|c|}{ Direct Microscopy } & Total \\
\cline { 2 - 3 } & Positive & Negative & \multirow{2}{*}{$35(100.0 \%)$} \\
\hline Masaleet & $14(40.0 \%)$ & $21(60.0 \%)$ & $42(100.0 \%)$ \\
\hline Hausa & $20(47.6 \%)$ & $22(52.4 \%)$ & $10(100.0 \%)$ \\
\hline Bega & $2(20.0 \%)$ & $8(80.0 \%)$ & $19(100.0 \%)$ \\
\hline Bargo & $6(31.6 \%)$ & $13(68.4 \%)$ & $13(100.0 \%)$ \\
\hline Marareet & $8(61.5 \%)$ & $5(38.5 \%)$ & $8(100.0 \%)$ \\
\hline Dago & $3(37.5 \%)$ & $5(62.5 \%)$ & $9(100.0 \%)$ \\
\hline Kebed & $7(77.8 \%)$ & $2(22.2 \%)$ & $7(100.0 \%)$ \\
\hline Fur & $3(42.9 \%)$ & $4(57.1 \%)$ & $6(100.0 \%)$ \\
\hline Gemer & $1(16.7 \%)$ & $5(83.3 \%)$ & $22(100.0 \%)$ \\
\hline $\begin{array}{l}\text { Western } \\
\text { tribes }\end{array}$ & $8(36.4 \%)$ & $14(63.6 \%)$ & $4(100.0 \%)$ \\
\hline Other & $3(75.0 \%)$ & $1(25.0 \%)$ & 175 \\
\hline Total & $75(42.9 \%)$ & $100(57.1 \%)$ & \\
\hline
\end{tabular}

\section{Discussion}

VL has been among the most important health problems in Sudan, particularly in the main endemic area in the eastern. Epidemiological, clinical spectrum, seasonal variation and risk factors estimation were found to be associated with high infection rates in Leishmania $[11,12]$. Surveys of VL in East Africa for estimation of the incidence of visceral leishmaniasis, found the annual VL incidence rate was; $15.700-30.300$ $[3,4]$.

In previous study, large survey has been conducted in eastern Sudan, which reported the incidence rate was found $6.91 \pm 0.82$ for the 3 years. While in this study, the incidence rate of visceral leishmaniasis from March 2014 to February 2015 was 42.8/1,000 person per year, which seems lower than the aforementioned studies. The differences in the incidence rates are most likely due to difference in study period, exposure to sand fly and the sample size in each study.

In 2006, a study was conducted in southern Gedaref state about the socio-economic status are all living in the context of a Muslim society. There is no schools other than a Holy Koran, which is exclusively for boys, and the women are not permitted to leave the house in some of the main tribes in the area, such as the Hausa $21 \%$ and the Tama $9 \%$. Thus, $90 \%$ had not received any formal education (i.e., they were either illiterate or had attended Holy Koran schools) [8]. Similarly, our study showed that, All population study which is a Muslim society, the educational status (Illiterate $66.3 \%$, Basic $30.9 \%$ and Secondary $2.9 \%$ ) and economic state (Poor 9.4\%, Mid 18.3\% and Rich 2.3\%).

In Brazil, a study by Brustoloni among 116 children suspected with $\mathrm{VL}$, the prevalence of VL was $83.6 \%$ detected by BMA, while in this study the prevalence by BMA was $57.1 \%$.

In this study the prevalence rate was calculated from 175 suspected cases, by LN or BM microscopically (gold standard techniques), it was $57.1 \%$ of total suspected cases who attended the rural hospital in Rahad river region. Another study was done to investigate theprevalence in Gedaref state, eastern Sudan in Rahad region where the prevalence rate was $33.9 \%$, Atbara $21.6 \%$ and Gedaref $10.6 \%$, the prevalence in Rahad region in our study was high compared with El Naiem study which indicate the highest present of endemicity in our study area.

In a study as a first experience with rK39 strip test in Sudan in 2001. The mean age of patients from the epidemic VL area was 17.3 years $(\mathrm{SD}=12.5)$, while patients from the endemic area were on average 10.8 years $(\mathrm{SD}=6.2)$ old $(\mathrm{P}=0.01)$, while in this study the mean age $16.5 \pm$ 12.6 and the sensitivity of the strip test $67 \%$ similar these study $79 \%$.

In another study reported from Eastern Sudan by the demonstration of $L$. donovaniamastigotes in lymph-node aspiration investigate whether the antibody response to VL infection assessed against the recombinant antigen (K39) the sensitivity of rk39 was $96 \%$.

In India, a study was performed to antibody-detecting rapid diagnostic tests (RDTs) against rK39 in serum are available to aid in 
Citation: Lana ME, Hshim BM, Abakar AD, Khalid KE, Elbadry AA, et al. (2017) Incidence of Leishmania Donovani Infection among Agropastoralists Tribes in Um-alkhare and Bazura Villages, Gedarif State, Eastern Sudan. J Trop Dis 5: 252. doi:10.4172/2329-891X. 1000252

Page 5 of 5

the diagnosis of VL, about $40 \%$ of suspected cases were positive for VL. We investigated for VL antibodies in serum specimens in our study cases using rK39 test, which showed prevalence rate $57.7 \%$ higher as compared with the prevalence rate from above mentioned studies [13].

A study in Nepal, reported rK39 was $97 \%$ sensitive and $71 \%$ specific, when used for screening of suspect patients in endemic areas, our data showed lower sensitivity which may be due to differences in species and virulence of the parasite Leishmania donovani.

The sensitivity and specificity of our data showed similar to the same result reported from Ethiopian population.

This study estimated the sensitivity and specificity of the rK39 strip test compared with the immuno-fluorescent antibody test and microscopy of bone marrow aspirate smears (the gold standard) in children with suspected VL. The sensitivity and specificity of the strip test were $82.4 \%$ and $100 \%$, this finding higher than our study [14].

In Bangladesh, Immuno-chromatographic strip test (ICT strip test) for the diagnosis of visceral leishmaniasis, parasitological confirmation was done by demonstration of leishmania donovani bodies in bone marrow or spleen aspiration in all cases, the sensitivity of this test was $96.6 \%$ and specificity was $98.3 \%$. The negative predictive value was $98.3 \%$ and for a positive predictive value was $96.6 \%$ [15].

Reasons for these discrepancies are not known, never the less, ethnically in the populations are quite different and therefore the role of genetic factors in susceptibility or resistance to Leishmania donovani cannot be ruled out.

\section{Conclusion}

In this study Hausa tribe has the highest infection (26.7\%) followed by Masaleet (18.7\%), this finding is in agreement with a study done by El Naiem [16].

Our study recommends the use of rk39 strip as non-invasive diagnostic technique for estimation of VL prevalence, since, the strip test is easy, quick, requires no technical facilities with higher sensitivity and specificity entails it to be the ideal test for the diagnosis of kalaazar in field level. The conventional PCR for detect more cases which record negative by direct microscopy or rk39. The variation between the infection resident tribes in endemic area should be examined genetically to detect the main cause to susceptibility of some without other.

\section{Acknowledgement}

The authors are indebted to the staff of Um-alkhare and Bazura Rural Hospitals in Gedarif State for their cooperation during the field work, and to the patients who participated in this study.

\section{Competing Interests}

The authors declare that they have no competing interests.

\section{References}

1. Banuls AL, Hide M, Prugnolle F (2007) Leishmania and the leishmaniases: A parasite genetic update and advances in taxonomy, epidemiology and pathogenicity in humans. Adv Parasitol 64: 1-458.

2. Desjeux P (2001) The increase in risk factors for leishmaniasis worldwide. Trans R Soc Trop Med Hyg 95: 239-243.

3. Alvar J, Velez ID, Bern C, Herrero M, Desjeux P, et al. (2012) Leishmaniasis worldwide and global estimates of its incidence. PloS One 7: e35671.

4. Alvar J, Yactayo S, Bern C (2006) Leishmaniasis and poverty. Trends Parasitol 22: 552-557.

5. Babiker ZO, Davidson R, Mazinda C, Kipngetich S, Ritmeijer K (2007) Utility of lymph node aspiration in the diagnosis of visceral leishmaniasis in Sudan. Am J Trop Med Hyg 76: 689-693.

6. Brustoloni YM, Cunha RV, Dorval ME, Oshiro ET, Pontes ER, et al. (2007) Comparison of conventional methods for diagnosis of visceral leishmaniasis in children of the Center-West Region of Brazil. Braz J Infect Dis 11: 106-119.

7. Chappuis F, Sundar S, Hailu A, Ghalib H, Rijal S, et al. (2007) Visceral leishmaniasis: what are the needs for diagnosis, treatment and control ? Nat Rev Microbiol 5: 873-882.

8. DA Silva MR, Stewart JM, Costa CH (2005) Sensitivity of bone marrow aspirates in the diagnosis of visceral leishmaniasis. Am J Trop Med Hyg 72: 811-814

9. Ejazi SA, Ali N (2013) Developments in diagnosis and treatment of visceral leishmaniasis during the last decade and future prospects. Expert Rev Anti Infect Ther 11: 79-98.

10. Gerstl S, Amsalu R, Ritmeijer K (2006) Accessibility of diagnostic and treatment centres for visceral leishmaniasis in Gedaref State, northern Sudan. Trop Med Int Heal 11: 167-175.

11. Khalil EA, Zijlstra EE, Kager PA, EL Hassan AM (2002) Epidemiology and clinical manifestations of Leishmaniadonovani infection in two villages in an endemic area in eastern Sudan. Trop Med Int Health 7: 35-44.

12. Mansour D, Abass EM, Mahamoud A, EL Harith A (2009) Qualitative and semi-quantitative comparison of an rK39 strip test and direct agglutination test for detection of anti-Leishmaniadonovani antibodies in the Sudan. Iran J Immunol 6: 208-215.

13. Mueller YK, Nackers F, Ahmed KA, Boelaert M, Djoumessi JC, et al. (2012) Burden of visceral leishmaniasis in villages of eastern Gedaref State, Sudan: An exhaustive cross-sectional survey 6: e1872.

14. Srivastava P, Dayama A, Mehrotra S, Sundar S (2011) Diagnosis of visceral leishmaniasis. Trans R Soc Trop Med Hyg 105: 1-6.

15. Zijlstra E, Nur Y, Desjeux P, Khalil E, ElHassan AM, et al. (2001) Diagnosing visceral leishmaniasis with the recombinant K39 strip test: experience from the Sudan. Trop Med Int Heal 6: 108-113.

16. Elnaiem DEA, Schorscher J, Bendall A, Obsomer V, Osman ME, et al. (2003) Risk mapping of visceral leishmaniasis: the role of local variation in rainfall and altitude on the presence and incidence of kala-azar in eastern Sudan. Am J Trop Med Hyg 68: 10-17. 